\title{
Volunteer stroke scheme for dysphasic patients with stroke
}

\author{
VALERIE EATON GRIFFITH， CHRISTINE L MILLER
}

The needs of the dysphasic patient with a stroke, in whom the effect of physical damage is so often intensified by loss of morale, are well recognised. Both the numbers who survive and the long periods for which support is needed create a problem that is unlikely to be relieved without help from the community. A pilot scheme using untrained volunteers working within a responsible organisation and co-operating with professionals was sponsored by the Chest and Heart Association* in 1973. The results of the first 16 months' work with 31 patients were reported in $1975 . .^{1}$ Since then the scheme has spread to 33 areas throughout Britain and by April 1980 had included 1013 patients and over 2000 volunteers. This report refers to 552 patients in the first five years of the scheme.

\section{General plan}

The Volunteer Stroke Scheme was based on the experience gained by untrained volunteers working with two dysphasic patients with stroke. ${ }^{2}$ The structure that proved successful in the pilot scheme has remained basically the same; the patient receives weekly visits from each member of a small team of volunteers and attends a weekly club.

The scheme in each area is run by a part-time paid supervisor under the direction of the originator of the scheme (VEG) and her assistant. Volunteers go into the homes as friendly neighbours, and they aim to stimulate the patient through their own as well as his interests. In addition to encouraging the use of speech they try to help with reading and writing, and practise with money and telling the time. They also try to develop memory and concentration, but above all they aim at

*Now the Chest, Heart, and Stroke Association (CHSA).

Epidemiological Research Laboratory, Central Public Health Laboratory, Colindale, London NW9 5HT

CHRISTINE L MILLER, BM, BCH, senior epidemiologist

Great Missenden, Buckinghamshire

VALERIE EATON GRIFFITH, originator of scheme increasing confidence and improving the quality of life for the patient and his family. The organisation and methods used by the volunteers have been described. ${ }^{1}$

\section{ADMINISTRATION AND COST}

The Chest, Heart, and Stroke Association is responsible for the Volunteer Stroke Scheme throughout Britain. Each individual scheme is set up within a health district or the equivalent, which brings an average of 26 patients into a scheme at any one time. The annual cost of an individual scheme in April 1980 was $£ 3500$ including the supervisor's part-time salary, running expenses, and transport; thus the annual cost for each patient was $£ 135$.

The association's policy is to finance the first 15-24 months of a new scheme at the current rate. Since 1978 most health authorities have agreed at the initial meeting to finance the scheme themselves after this period, provided it has been successfully established. Payment is made to the association, which is responsible for maintaining standards.

\section{Patients}

Of the 552 patients $304(55 \%)$ were men, and in both men and women the highest proportion of cases occurred in the 65-74 agegroup (table I). Because there are more women than men in the population as age increases, ${ }^{3}$ the actual figures do not give an accurate picture of the male to female difference, especially in ages over 65 . For example, in the $\mathbf{7 4}$ and over age group, although there are twice as

TABLE I-Sex and percentage of patients in each age group on entry to the scheme

\begin{tabular}{lcccccc}
\hline & $\begin{array}{c}\text { Total } \\
\text { Noof } \\
\text { cases }\end{array}$ & $<45$ & $45-54$ & $55-64$ & $65-74$ & $\geqslant 74$ \\
\hline Men & 304 & 5 & 13 & 30 & 43 & 99 \\
Women & 248 & 9 & 9 & 28 & 32 & 22 \\
\hline
\end{tabular}


many cases in women, the incidence is slightly higher in men. Overall there is little difference in the rates under 45 and above 74 , but there is an excess of over $50 \%$ in men between 45 and $74: 48 \%$ of the men and $46 \%$ of the women were under 65 on entry to the scheme.

\section{INTERVAL BETWEEN STROKE AND ENTRY TO THE SCHEME}

In half the patients the interval between stroke and entry to the scheme was less than a year and in over half of these it was under six months. In 38\% it was between one and five years and in $11 \%$ over five years. In a few cases the interval was more than 10 years. part-time work, seven to their previous occupations for a few hours a week, five in sheltered workshops, and three to very minor jobs:

\section{ASSESSMENT OF IMPROVEMENT}

For 350 patients who had completed six months in the scheme, comments on progress, both in speech and general confidence, were $\bar{O}$ requested from the general practitioner, speech therapist, family, and $\frac{\partial}{2}$ volunteers. The results are shown in table II. Although the number of reports from each source varied, all agreed that $90-95^{\circ}$, of of patients

TABLE II-Number of reports available and percentage improved in speech and general confidence

\begin{tabular}{|c|c|c|c|c|c|c|c|c|}
\hline & \multicolumn{2}{|c|}{ General practitioner } & \multicolumn{2}{|c|}{ Speech therapist } & \multicolumn{2}{|c|}{ Family } & \multicolumn{2}{|c|}{ Volunteers } \\
\hline & $\begin{array}{c}\text { Reports } \\
\text { available }\end{array}$ & Improved & $\begin{array}{l}\text { Reports } \\
\text { available }\end{array}$ & Improved & $\begin{array}{c}\text { Reports } \\
\text { available }\end{array}$ & Improved & $\begin{array}{l}\text { Reports } \\
\text { available }\end{array}$ & Improved \\
\hline \multirow{2}{*}{$\begin{array}{l}\text { Speech } \\
\text { Genieral } \\
\text { confidence }\end{array}$} & 255 & 78 & 135 & 70 & 254 & 84 & 350 & 80 \\
\hline & 261 & 95 & 128 & 95 & 270 & 94 & 350 & 90 \\
\hline
\end{tabular}

\section{DOMICILE}

At the time they joined the scheme 429 patients ( $78 \%$ ) were living at home with their families, $68(12 \%)$ at home on their own, and 55 $(10 \%)$ in a residential home or long-stay hospital.

SPEECH

According to professional diagnosis, 513 patients $(93 \%)$ had dysphasia, in many cases with dyspraxia or dysarthria, or both. Some 39 patients $(7 \%)$ had dysarthria only.

The degree of severity of the speech and comprehension problems of each patient was recorded from the speech therapist's assessment wherever available, or from a doctor's report. Of the 552 patients, 246 $(45 \%)$ were considered to have severe speech problems and of these, comprehension was also affected in $103(42 \%)$

\section{PHYSICAL STATE}

Five hundred and fifteen patients $\left(93^{\circ} \%\right)$ had hemiplegia affecting the dominant side; in all but four this was the right side. Twenty-five $(4 \%)$ had left hemiplegia with right dominance and nine the reverse. Two with left dominance had paralysis of both sides and one formerly ambidextrous patient had right hemiplegia.

In 246 patients $(45 \%)$ the paralysed hand was useless. Sixty-seven patients $(12 \%)$ were chair-bound; none was permanently bed-bound. One hundred and one patients $\left(18^{\circ} \%\right)$ had had strokes before the one bringing them into the scheme.

\section{Outcome and assessment of improvement}

\section{DEATHS, FURTHER ILLNESS, AND REASONS FOR LEAVING THE SCHEME}

Of the 552 patients 69 died $(13 \%), 10$ from further strokes and the rest from other causes. Eighty-six other patients left the scheme; 20 were too ill to continue (13 after further strokes) and 50 improved and no longer needed help. Of the remainder, nine had moved to other areas and only seven did not wish to continue. Thus of the 552 patients, 397 remained in the scheme, including nine who had had further strokes.

\section{RETURN TO WORK}

Four of the 146 men under retirement age returned to full-time work $(3 \%)$, two of them aged 56 and 48 with slight speech problems to their previous jobs. Fifteen other patients aged 39-67 returned to showed general improvement and $70 \%$ or more improved in speech. The following case histories illustrate some aspects.

Man aged 57-Interval from stroke to entry to the scheme, six months. Condition on entry: severe expressive and receptive dysphasia with dyspraxia, useless right hand, unable to do a four-piece jigsaw, depressed, and confused. Speech therapy had stopped because, as his therapist wrote: "My efforts only depressed him more and he refused to try anything. As the prognosis was very poor I referred him to the Volunteer Stroke Scheme when it started, although I thought the possibility of improvement was fairly slim. The volunteers began visiting him and he attended their club. I saw him $\subseteq$ every few months and noticed a gradual change in him. He gained a great deal of motivation from his volunteers, especially the gentleman who had recovered from a stroke; this was one of his most important relationships. His insight into his situation improved and his facial expressions showed more understanding, contentment, and co-operation. His ability to co- $\bar{\partial}$ ordinate sounds improved-one of his volunteers worked on this specifically. Through painting and drawing, both at the club and with an individual (D) volunteer, his perceptual motor problems began to be partly resolved. He began to associate objects and pictures and even painted a few still lifes. $\overrightarrow{\vec{D}}$ This type of help is not available anywhere other than with the Volunteer Stroke Scheme and I think that it was invaluable with this man."

Man aged 63-Interval from stroke one year seven months. Condition on entry: severe expressive and some receptive dysphasia, diabetes, and pernicious anaemia. His speech therapy stopped when he entered the scheme. His speech therapist saw him again after 12 months and noticed some improvement in speech, as well as reading and writing on which the volunteers had been working. His confidence had increased sufficiently for him to answer the phone, which she commented was entirely due to the work of the volunteers.

Man aged 72-Interval from stroke six months. Condition on entry: severe dysphasia and dyspraxia, poor eyesight, deteriorating use of right hand. $\mathrm{He}$ was having speech therapy when he entered the scheme, and both the patient $\mathrm{O}$ and his wife were doubtful whether the volunteers could help. After $14 \mathrm{~N}$ months in the scheme he was no longer withdrawn and embarrassed at his $\sigma$ inability to speak. The therapist commented that the volunteers had helped $D$ him to overcome his intense frustration at being unable to express himself, 윽 and he now laughed when he could not find words.

Man aged 44-Interval from stroke (his fourth) 18 months. Condition on $\mathbb{O}$ entry: severe expressive and receptive dysphasia, useless right hand, de- N pressed, withdrawn, and aggressive. His speech therapy had finished two $O$ years previously, and his wife was at breaking point. After a few months' working with his three volunteers he was able to match words to pictures, to follow simple commands, and to mime. He learnt to play chess and other $\mathbb{D}$ games, and after visits to the club became alert and interested, and attempted to participate. The district nurse commented on his increased confidence and the great benefit the volunteers had brought both to the patient and his wife.

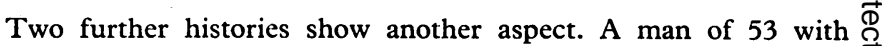
moderate dysphasia, dyspraxia, and dysarthria was so frustrated and $\overrightarrow{\mathbb{D}}$ aggressive that on the breakup of his marriage he was admitted to a geriatric ward. After two years in the scheme his self-control and morale had improved sufficiently for him to move out to a council $\delta$ flat. A man of 52 with severe dysphasia and a useless right hand and leg remained in hospital for 12 months longer than was clinically necessary because his flat was inaccessible to him, and his morale was so poor. After some months with his volunteers the social worker noticed that his greatly improved morale had led to him making the most of his remaining mobility, and sheltered accommodation was arranged. 


\section{Discussion}

Over the past five years conventional treatment for patients dysphasic after a stroke has been questioned and the importance of improving morale has been recognised. ${ }^{4}$ One study showed that untrained volunteers made a valuable contribution to the return of social confidence ${ }^{6}$ and another that treatment by professional and untrained volunteers provided essentially the same benefit. ${ }^{7}$ The difficulties of assessing the effect of rehabilitation are well recognised. ${ }^{4}{ }^{8}$ Nevertheless, a controlled trial has shown more frequent language recovery in treated patients compared with those untreated, provided the course continued for at least six months, with no fewer than three individual sessions a week. ${ }^{8}$ Whether this treatment must be exclusively professional is more doubtful. After a progress report ${ }^{9}$ another study in 20 centres has begun to evaluate the contribution of professional speech therapists compared with that of untrained volunteers.

Our paper makes no attempt to be a controlled study. It is an account of the work of volunteers in the association's Volunteer Stroke Scheme over nearly seven years, and it shows again what can be achieved by those with no specific training. Few supervisors or volunteers had previous experience in this difficult topic, but by using the simple methods that succeeded with the original patients together with their common sense and perception, they have broken through the daunting barrier of loss of communication. Weekly visits over many months provide a unique opportunity to observe the patient in his own home and to perceive how best to encourage his progress; the kindling of interest is still the essential starting point.

A feature in the development of the scheme is that, although it began in a largely middle-class area with a tradition of voluntary service, it has been shown to work in very different circumstances, including deprived urban areas and isolated rural communities. No established scheme has yet failed, and supervisors and volunteers have been found in such widely contrasting places as Portsmouth, the Highlands, Tameside, Glasgow, and South-east Cardiff. Similar schemes have started in Guernsey, USA, Canada, New Zealand, and Western Australia.

Two important points emerged from the first five years of the scheme. Firstly, only four of the 146 men under retirement age returned to full-time work, of whom only two (neither with severely affected speech) went back to their former jobs; even the return to part-time work was a rarity. Secondly, only 69 patients died even though 80 patients were over 74 when they entered the scheme. Both points have an important bearing on the numbers of patients dysphasic after a stroke who survive and need continuing help. Although volunteers often stay with their patient for several years they cannot continue indefinitely. The transition must be gradual, however, and the scheme aims to leave both patient and family with sufficiently improved morale for the patient to be accepted back into the community.

"Improvement" in these patients is hard to define. For instance, should it be limited to the recognition and use of a few more words, or is it the improvement in morale which can be a step towards a restored human being, even though the gain in speech is slight ? Basso has confirmed that social readjustment may be independent of the return of language. ${ }^{8}$ In financial terms improved morale can mean vacation of a hospital bed, and support for the family can prevent the collapse of the hardpressed partner with the inevitable readmission of the patient. The patients' histories illustrate these points.

Comments from professionals confirmed general improvement in $95 \%$ of the patients they saw, and speech therapists found improvement in speech in $70 \%$. In some of these cases professional treatment had stopped and no further improvement had been expected; in others the expected deterioration had not occurred. The professional comments generously acknowledged the contribution of the volunteers.

The scheme has shown that it can provide guidance and an efficient framework within which volunteers are free to use their initiative. This they evidently find satisfactory. It has also shown that patients can be given an individual service that is not available elsewhere for the current annual cost of $£ 135$ a patient.

Since 1973 the scheme has grown in size and also in new ideas and methods. The transition has been made from a small beginning to an organisation caring for over 1000 patients without loss of the original concept, which is to stimulate and broaden the life of each patient.

Requests for reprints: Chest, Heart, and Stroke Association, Tavistock House North, Tavistock Square, London WC1H 9JE.

\section{References}

${ }^{1}$ Eaton Griffith V. Volunteer scheme for dysphasic and allied problems in stroke patients. $B r$ Med F 1975 ;iii :633-5.

${ }^{2}$ Eaton Griffith V. A stroke in the family. London: Wildwood, 1975.

${ }^{3}$ Office of Population Censuses and Surveys. Population trends. 1980;20:33.

4 Anonymous. Recovery patterns and prognosis in aphasia. $\mathrm{Br} \mathrm{Med} \mathcal{F} 1977$; ii :848-9.

${ }^{5}$ Hopkins A. The need for speech therapy for dysphasia following stroke. Health Trends 1975; 7:58-60.

${ }^{6}$ Lesser R, Watt $M$. Untrained community help in the rehabilitation of stroke sufferers with language disorder. $B r$ Med f 1978 ;ii:1045-8.

7 Meikle M, Wechsler E, Tupper A, et al. Comparative trial of volunteer and professional treatments of dysphasia after stroke. Br Med $\mathcal{F} 1979$;ii: 87-9.

${ }^{8}$ Basso A, Capitani E, Vignolo LA. Influence of rehabilitation on language skills in aphasic patients. A controlled study. Arch Neurol 1979;36: 190-6.

${ }^{9}$ David RM, Enderby P, Bainton D. Progress report on an evaluation of speech therapy for aphasia. Br $\mathcal{F}$ Disord Commun 1979;14:85-8.

(Accepted 8 October 1980)

Is asparagus a "genemarker" in that only certain people produce the characteristic smelly urine caused by the presence of aspartic acid? Does this characteristic, if present, diminish with age?

Forty-six of 115 individuals tested by Allison and McWhirter ${ }^{1}$ produced the characteristically smelly urine after ingesting asparagus. Limited family information suggested that "non-excretors" are autosomal Mendelian recessives while "excretors" are Mendelian dominants. It had been thought that methyl mercaptan (methanethiol) was the chemical responsible for the smell. Complex investigations by White ${ }^{2}$ failed to confirm the presence of this compound in the urine of subjects who had eaten asparagus. He did, however, find S-methyl thioacrylate and its methanethiol addition product S-methyl 3-(methyl thio) thiopropionate. When these compounds were synthesised and added to non-odorous urine from subjects who had not eaten asparagus the characteristic smell detected after asparagus ingestion was observed. In this work the excretion of these compounds was not shown to be polymorphic in man. The metabolic origin of these compounds is unknown. Usually a subject is characterised as excreting or not excreting smelly urine after asparagus as a result of reporting his own observations. Lison $e t a l^{3}$ have investigated this aspect. They prepared serial dilutions of urine passed by a man who had eaten asparagus. These serial dilutions were smelled by 307 people and a "smell-threshold" determined. The thresholds tended to be a little lower below the age of 40 years. The frequency distribution histogram of the smell threshold is bimodal with 30 subjects categorised as "smellers" and 277 "non-smellers." It is not known if this is a genetic polymorphism, and if it is the gene frequencies are clearly different to those tested by Allison and McWhirter. ${ }^{1}$

Thus the genetics are not clear. The genetic polymorphism reported by Allison and McWhirter ${ }^{1}$ is unconfirmed, and the interpretation of "self-reporting" is clouded in view of the work of Lison $e t$ al. ${ }^{3}$ The phenomenon described by them represents a quite different phenomenon which may, if confirmed, turn out to be a new genetic polymorphism.

${ }^{1}$ Allison AC, McWhirter KG. Two unifactorial characters for which man is polymorphic. Nature 1956;178:748-9

. eaten asparagus. Science 1975;189:810-1

, ability to smell urinary metabolites of asparagus. $\mathrm{Br} \mathrm{Med} \mathcal{f}$ (in press). 